\title{
Gigant Transethmoidal Meningoencephalocele Operated by Full Endonasal Endoscopic Approach: Case Report
}

\author{
Omar Lopez Arbolay, Jorge Rojas Manresa, \\ Justo Gonzalez Gonzalez, and Jose Luis Bretón Rosario \\ Neurosurgery Department of Hermanos Ameijeiras Hospital, Havana 10348, Cuba \\ Correspondence should be addressed to Omar Lopez Arbolay, arbolay@infomed.sld.cu
}

Received 18 September 2011; Accepted 6 December 2011

Academic Editor: Mark E. Shaffrey

Copyright $\odot 2012$ Omar Lopez Arbolay et al. This is an open access article distributed under the Creative Commons Attribution License, which permits unrestricted use, distribution, and reproduction in any medium, provided the original work is properly cited.

\begin{abstract}
Intranasal meningoencephaloceles have historically been managed by neurosurgeons, although their main clinical manifestations are rhinological. Recent advances in endoscopic skull base surgery has significantly improved the treatment of these lesions and consequently diminished appreciable surgical morbidity. We report an ethmoidal meningoencephalocele case operated on by endonasal endoscopic approach for removal of the lesion and reconstructing the associated skull base. From this experience, we conclude that removal of the lesion and watertight closure of the skull base irrespective of the size of the mass and anterior skull base defect are the operation's most important aspects.
\end{abstract}

\section{Introduction}

Intranasal meningoencephaloceles are an infrequent condition characterized by protrusion of meningeal and brain tissue through a skull-base defect. Congenital anomalies are the main cause [1], but they may have also a traumatic or a spontaneous origin $[2,3]$. According to the location, meningoencephaloceles are classified in: occipital, cranial vault, posterior fosse, and basal. The incidence of this rare condition range between 0.1 to 0.5 of 1,000 birthrates. Basal meningoencephalocele represents $1.5 \%$ of all these lesions, and are classified as: transethmoidal, sphenoethmoidal, transsphenoidal, and frontosphenoidal $[4,5]$. In transethmoidal type, a defect on the cribriform plate is observed, commonly small and limited to one side [6]. Nasal CSF leakage, headache, and nasal obstruction, are frequently the chief complaints. Rarely, seizure is observed but meningitis is common.

On physical examination, it is possible to find an intranasal mass, leakage of a clear liquid across the nose, olfaction lost, and other craniofacial defects in the congenital encephaloceles. Some studies may be performed to establish the diagnosis, but magnetic resonance imaging (MRI) is the leading investigation because it is able to show the protruded brain tissues and their relationship with neighboring structures. A special useful test to demonstrate the bony defect will be the CT scan with bone window [1].

We present a case with transethmoidal meningoencephalocele that was operated on by endonasal endoscopic technique.

\section{Clinical Case}

Our case is a 55 -year-old female patient, who 23 years ago underwent transsphenoidal surgery for an intrasellar cyst. Five years after the surgery, hydrocephalus with cerebral spinal fluid leakage occurred and it was resolved by the placement of a ventriculoperitoneal shunt. Computed tomography did not define the bone defect at the site of previous surgery at that time. The patient presented before us, two years ago, with recurrent profuse rhinorrhea and nasal obstruction. She was admitted in Neurosurgical Department with headache, fever and vomiting, and bacterial meningitis which was successfully treated with antibiotics was diagnosed. MRI revealed protrusion of the brain and meninges from the anterior cranial fossa to the upper right nasal cavity. 


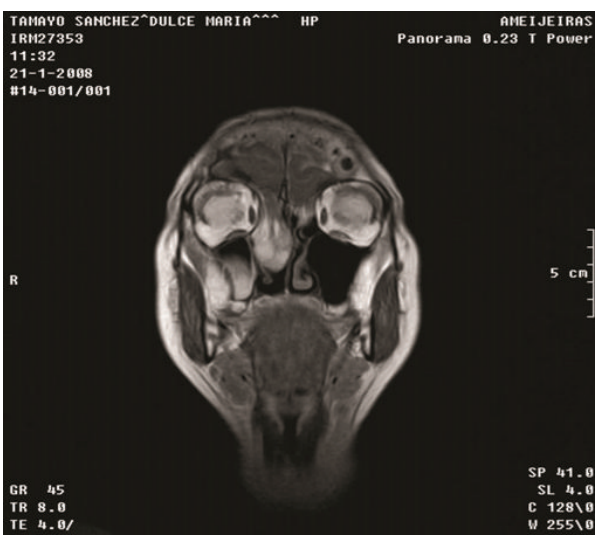

FIGURE 1: MRI, coronal view.

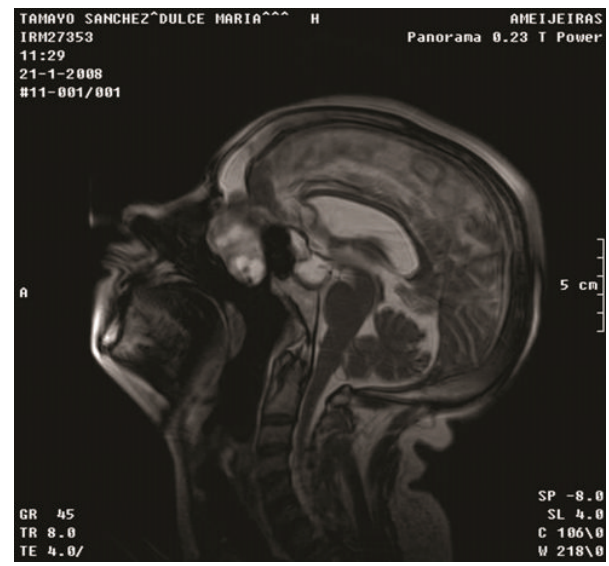

FIGURE 2: MRI, sagital view.

The T1-weighted sequences showed downward herniation of the ethmoidal roof on the right nasal cavity and T2-weighted coronal, and sagital imaging confirmed a liquid-filled mass in the right ethmoidal sinus and nasal cavity projecting through a defect in the ethmoidal roof (Figures 1 and 2). Computed tomography confirmed these findings (Figure 3 ).

An extended endonasal endoscopic approach to the anterior cranial base was practiced. A big meningoencephalocele within right nasal cavity was found (Figure 4). By using bipolar forceps the lesions were reduced. Middle turbinate was atrophic and middleward displaced. When the lesion was completely removed, a bony defect at the junction of ethmoidal sinus and posterior wall of the frontal bone were observed (Figure 5). This was reconstructed inlaying a free intradural fat graft and an epidural layer of bone, which was then covered with a nasoseptal flap. This was supported with balloon of 12 French Foley catheter in order to press the multilayer reconstruction against the defect. The patient had an uneventual recovery. There were no cerebrospinal rhinorrhea or any other complications and the patient was discharged six days after the surgery.

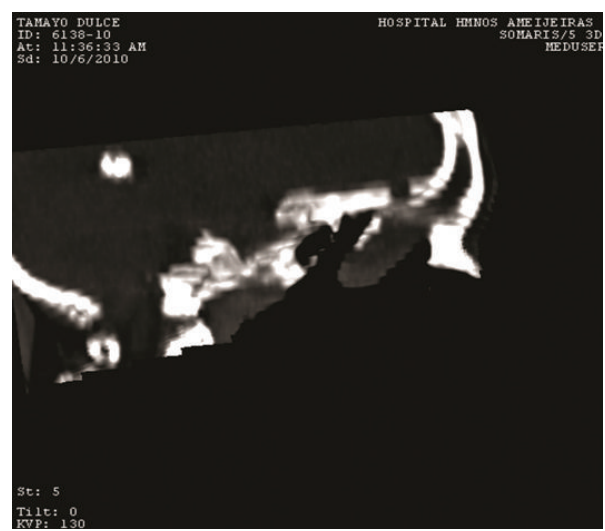

Figure 3: CT scan.

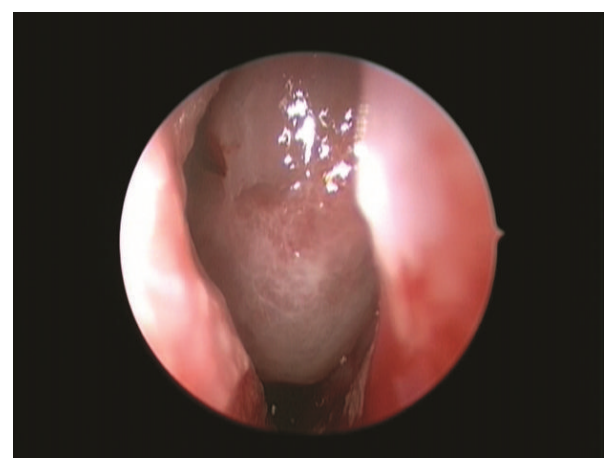

FIGURE 4: Endoscopic view of big meningoencephalocele within right nasal cavity.

\section{Discussion}

A multidisciplinary management is recommended in the diagnosis and treatment of meningoencephalocele. Surgical procedures include removal and anterior fossa defect reconstruction by craniotomy and more recently endonasal endoscopic resection and repair or combination of these two techniques to remove the lesion and repair the defect [7-14].

Endonasal endoscopic procedures and special development of extended endonasal endoscopic approaches have increased the interest on treating this kind of lesion. That is why the treatment of meningoencephaloceles has become more popular.

As the first step in the surgery, meningoencephalocele is carefully and gradually removed using bipolar cauterizing up to the level of the skull base. Then, mucosa surrounding skull-base defect is removed and the defect is prepared for the graft.

Selection of the graft material depends on the defected size and configuration, underlying pathophysiology and the surgeon's preference [15]. A multilayer repair is preferred not only to stop the CSF leak, but to reinforce the thin skull base and prevent meningoencephalocele recurrence [16, 17].

Autologous-free or pedicellate mucoperichondrial grafts, fascia, turbinate grafts, cartilage grafts, pericranial-galeal, and bone grafts have all been used successfully. Heterologus 


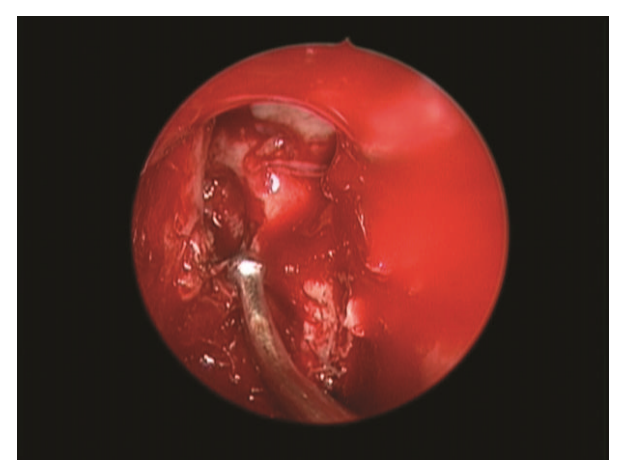

Figure 5: Endoscopic view of bony defect at the junction of ethmoidal sinus and posterior wall of the frontal bone.

materials have also been used subdural as collagen matrix (Duragen, Integra Life Sciences) and no cells dermis grafts (Alloderm, Lifecell Corp.) [15]. Recently, reconstruction of skull base using vascularized pedicellar flap has been described. Nasoseptal and inferior turbinate flap seem to be the most useful. Reconstruction of the cranial base using vascularized tissue promotes fast and complete healing, preventing complications caused by persistent communication between the cranial cavity and the sinonasal tract [18-21].

We considered that best option for repairing the skullbase defect in this case was to use a multilayer grafts. We used a free inly fat graft (intradural), then an inlaid epidural bone graft, and, after that, we covered it with a big vascular pedicellar nasoseptal flap to prevent a recurrent brain herniation and CSF leakage.

Historically, lumbar drainage of CSF has been used after surgery as an adjoined action to surgical repair. Nevertheless, the indications for a postoperative lumbar drainage have been debated and are very controversial in the literature $[22,23]$. The lumbar drainage is used depending on the surgeon's preference. We have adopted the use of the blown balloon to support the multilayer reconstruction because it counteracts gravity and the pulsations of the brain, mitigates graft migration, and prevents development of a channel of fluid. It is usually removed at the fifth day.

Surgical follow-up and postoperative care are always very important; it includes bed rest with the head elevated $30^{\circ}$ for 2 weeks and the use of laxatives or stool softeners. In the absence of obvious infection the prevention with antibiotic is fully justified but further studies are necessary to prove its efficacy [24].

\section{Conclusions}

Endonasal endoscopic approach makes it possible for a direct work and total removal of ethmoidal meningoencephaloceles. A nasoseptal flap allows repairing the defect and practicing a watertight closure of the skull base reducing the rate of postoperative CSF fistulae.

\section{References}

[1] P. Garg, V. Rathi, S. K. Bhargava, and A. Aggarwal, "CSF rhinorrhea and recurrent meningitis caused by transethmoidal meningoencephaloceles," Indian Pediatrics, vol. 42, no. 10, pp. 1033-1036, 2005.

[2] S. Badiane, K. Kalangu, Y. Kato, and G. Dechambenoit, "Encephaloceles," in Essential Practice of Neurosurgery, pp. 12821289, Access Publishing Co., 2009.

[3] T. H. Yang, S. Y. Jeong, and S. Y. Oh, "Recurrent Streptococcus Pneumoniae Meningoencephalitis in a patient with a Transethmoidal Maningoencephalocele," The Journal of Clinical Neurology, vol. 4, no. 1, pp. 40-44, 2008.

[4] J. T. Rutka, C. Carlotti, and M. Iantoska, "Development and acquired anomalies," in Youmans Neurological Surgery, W. H. Richard, Ed., pp. 3198-3213, 5th edition, 2004.

[5] M. S. Greenberg, Handbook of Neurosurgery, Thieme, New York, NY, USA, 6th edition, 2006.

[6] A. Kubo, K. Sakata, J. Maegawa, and I. Yamamoto, “Transethmoidal meningoencephalocele in an elderly woman: case report," Neurologia Medico-Chirurgica, vol. 45, no. 6, pp. 322326, 2005.

[7] F. Aderito, J. Minaret, S. Aidmar, and F. Medina, "Giant Ethmoid Meningoencephalocele," Journal of Otorhinolaryngology, vol. 10, no. 2, 2009.

[8] B. McCormack, P. R. Cooper, M. Persky, and S. Rothstein, "Extracranial repair of cerebrospinal fluid fistulas: technique and results in 37 patients," Neurosurgery, vol. 27, no. 3, pp. 412-417, 1990.

[9] E. E. Dodson, C. W. Gross, J. L. Swerdloff, and L. M. Gustafson, "Transnasal endoscopic repair of cerebrospinal fluid rhinorrhea and skull base defects: a review of twenty-nine cases," Otolaryngology-Head and Neck Surgery, vol. 111, no. 5, pp. 600-605, 1994.

[10] M. Gjuric, H. Keimer, U. Goede, and M. E. Wigand, "Endonasal endoscopic closure of cerebrospinal fluid fistulas at the anterior cranial base," Annals of Otology, Rhinology and Laryngology, vol. 105, no. 8, pp. 620-623, 1996.

[11] S. Schmerber, C. Righini, J. P. Lavielle, J. G. Passagia, and E. Reyt, "Endonasal endoscopic closure of cerebrospinal fluid rhinorrhea," Skull Base, vol. 11, no. 1, pp. 47-58, 2001.

[12] C. Bachert, B. Verhaeghe, P. Van Cauwenberge, and J. Daele, "Endoscopic Endonasal Surgery (EES) in skull base repairs and CSF leakage," Acta Oto-Rhino-Laryngologica Belgica, vol. 54, no. 2, pp. 179-189, 2000.

[13] M. C. Noone, J. D. Osguthorpe, and S. Patel, "Pericranial flap for closure of paramedian anterior skull base defects," Otolaryngology-Head and Neck Surgery, vol. 127, no. 6, pp. 494-500, 2002.

[14] A. Tabaee, T. L. Kassenoff, A. Kacker, and V. K. Anand, "The efficacy of computer assisted surgery in the endoscopic management of cerebrospinal fluid rhinorrhea," OtolaryngologyHead and Neck Surgery, vol. 133, no. 6, pp. 936-943, 2005.

[15] B. George, P. Jamet, and P. Frerebeau, "Materials for osteodural reconstruction in the cranium: an update," Acta Neurochirurgica, vol. 35, pp. 145-151, 1989.

[16] V. K. Anand, R. K. Murali, and M. J. Glasgold, "Surgical decisions in the management of cerebrospinal fluid rhinorrhoea," Rhinology, vol. 33, no. 4, pp. 212-218, 1995.

[17] B. A. Senior, K. Jafri, and M. Benninger, "Safety and efficacy of endoscopic repair of CSF leaks and encephaloceles: a survey of the Members of the American Rhinologic Society," American Journal of Rhinology, vol. 15, no. 1, pp. 21-25, 2001.

[18] F. S. G. Fortes, R. L. Carrau, C. H. Snyderman et al., "The posterior pedicle inferior turbinate flap: a new vascularized flap for skull base reconstruction," Laryngoscope, vol. 117, no. 8, pp. 1329-1332, 2007. 
[19] G. Hadad, L. Bassagasteguy, R. L. Carrau et al., "A novel reconstructive technique after endoscopic expanded endonasal approaches: vascular pedicle nasoseptal flap," Laryngoscope, vol. 116, no. 10, pp. 1882-1886, 2006.

[20] C. D. Pinheiro-Neto, D. M. Prevedello, R. L. Carrau et al., "Improving the design of the pedicled nasoseptal flap for skull base reconstruction: a radioanatomic study," Laryngoscope, vol. 117, no. 9, pp. 1560-1569, 2007.

[21] C. H. Snyderman, A. B. Kassam, R. Carrau, and A. Mintz, "Endoscopic reconstruction of cranial base defects following endonasal skull base surgery," Skull Base, vol. 17, no. 1, pp. 73-78, 2007.

[22] S. A. Shapiro and T. Scully, "Closed continuous drainage of cerebrospinal fluid via a lumbar subarachnoid catheter for treatment or prevention of cranial/spinal cerebrospinal fluid fistula," Neurosurgery, vol. 30, no. 2, pp. 241-245, 1992.

[23] R. R. Casiano and D. Jassir, "Endoscopic cerebrospinal fluid rhinorrhea repair: Is a lumbar drain necessary?" Otolaryngology-Head and Neck Surgery, vol. 121, no. 6, pp. 745-750, 1999.

[24] A. Kassam, A. J. Thomas, C. Snyderman et al., "Fully endoscopic expanded endonasal approach treating skull base lesions in pediatric patients," Journal of Neurosurgery, vol. 106, supplement 2, no. 2, pp. 75-86, 2007. 


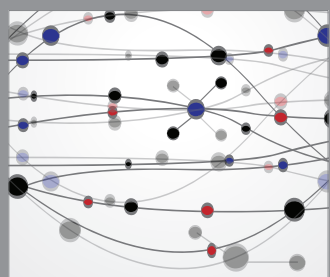

The Scientific World Journal
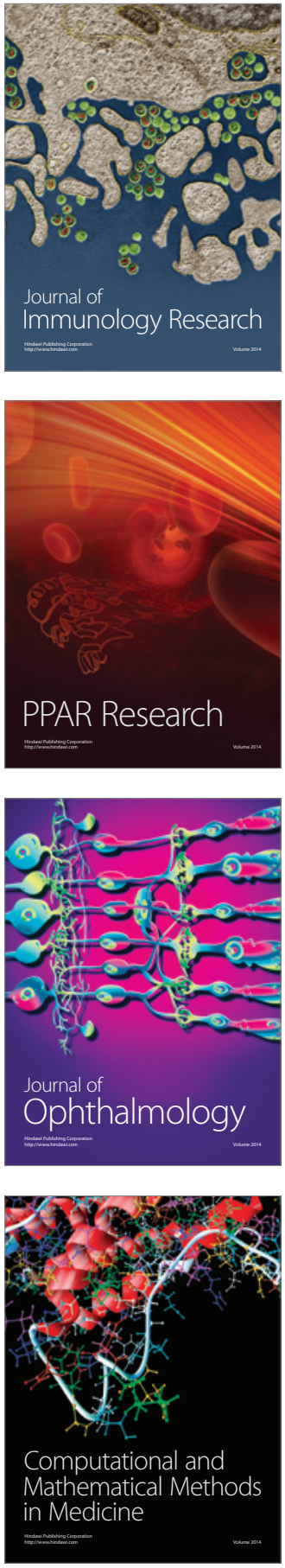

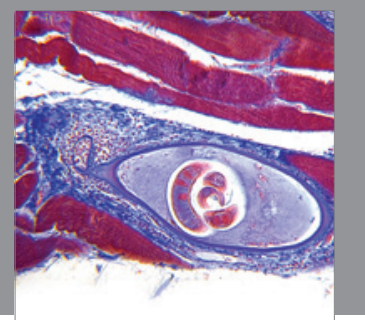

Gastroenterology

Research and Practice
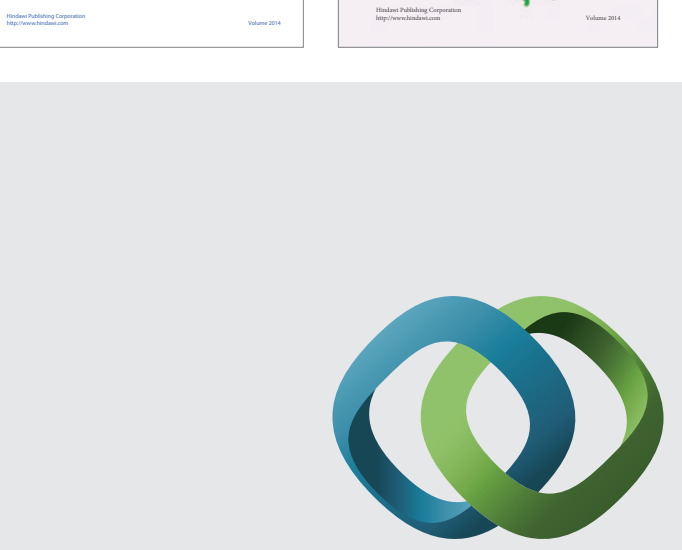

\section{Hindawi}

Submit your manuscripts at

http://www.hindawi.com
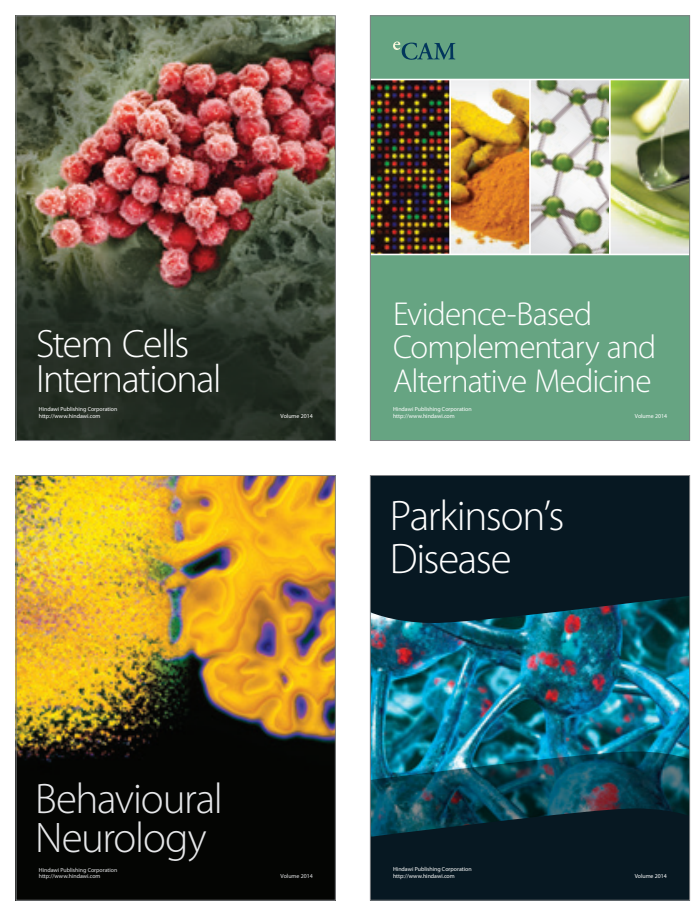

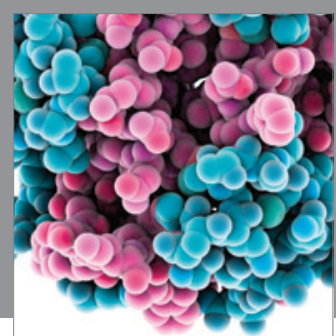

Journal of
Diabetes Research

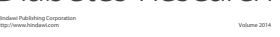

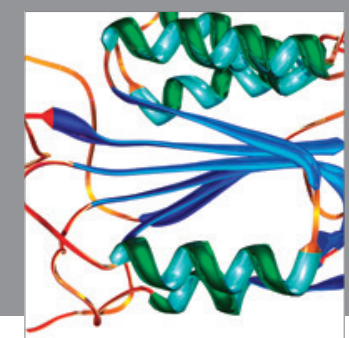

Disease Markers
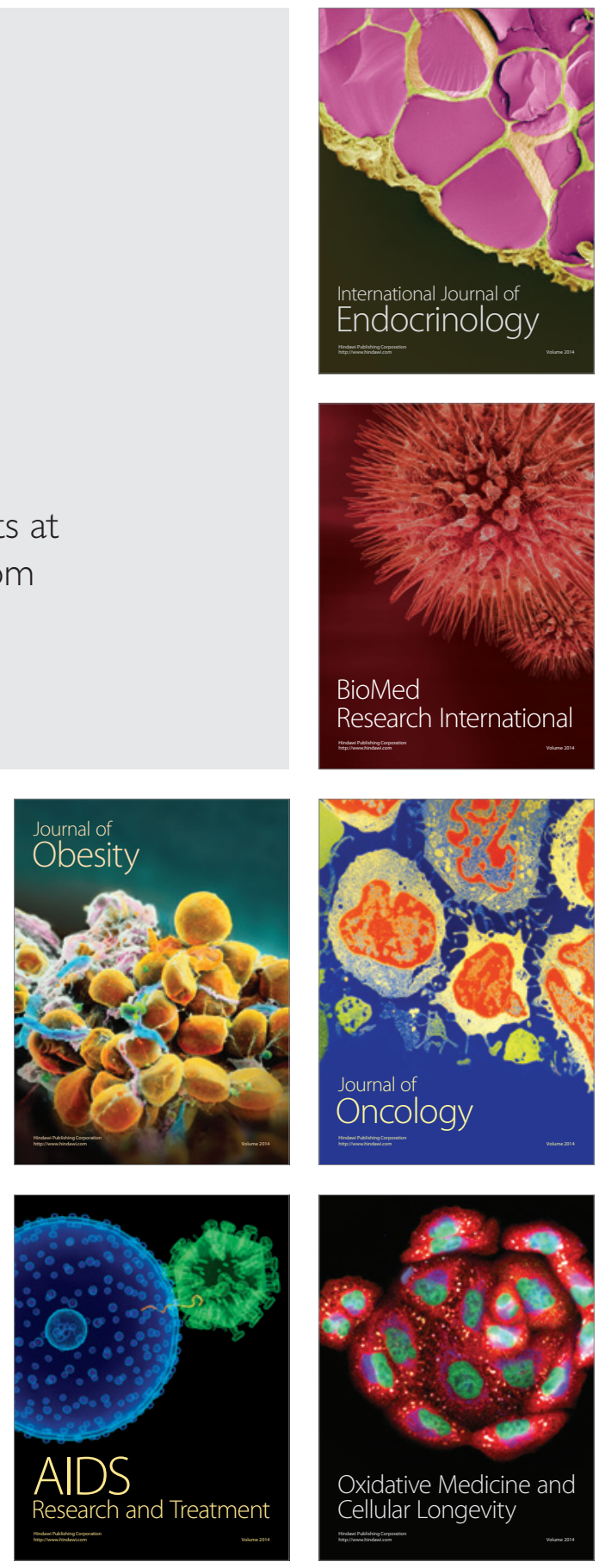